\title{
THE ROLES OF PLANT HORMONES IN THE GROWTH OF THE COROLLA OF GAILLARDIA GRANDIFLORA (ASTERACEAE) RAY FLOWERS ${ }^{1}$
}

\author{
Ross E. KonING ${ }^{2}$ \\ Department of Botany, University of Michigan, Ann Arbor, Michigan 48109
}

\begin{abstract}
A B S T R A C T
Corolla elongation and the roles of plant hormones in this process in Gaillardia grandiflora Van Houtte ray flowers were examined. The sterile ray flowers elongated during a 2-day period, and corolla growth was accompanied by fresh and dry weight increases and epidermal cell elongation (greatest near the base of the corolla) but not by cell division. Corollas excised from young ray flowers were measured during treatment in vitro with solutions of plant growth regulators. They elongated in response to gibberellins and fusicoccin but did not respond to auxins, cytokinins, abscisic acid, ethylene, or inhibitors of ethylene biosynthesis. Sequential and simultaneous hormone applications indicated no additive or synergistic effects between hormones, but auxin did reduce gibberellin-promoted growth. Analyses of endogenous auxins showed no significant variation, and ethylene production decreased prior to elongation, while a 20-fold increase in endogenous gibberellin activity was observed just prior to rapid corolla elongation. It appears that corolla growth in Gaillardia is accomplished by an increase in gibberellin activity alone, that multiple hormone interactions are not important in the control of corolla growth, and that part of the mode of action of gibberellin is acid-induced growth.
\end{abstract}

THE FLOWERING PROCESS has at least five sequential phases of development: flower induction, flower primordia differentiation, flower opening, anthesis and pollination, and flower senescence. The process of flower opening is in turn a sequence of several elongation and expansion processes which varies from species to species. In the Asteraceae, the inflorescence is usually composed of two flower types: the disc flowers (which are perfect and have a greatly reduced corolla), and the ray flowers (which are sterile and have a much larger corolla). The roles of plant hormones in the flower-opening processes of Gaillardia disc flowers have been described previously (Koning, 1983a, b). The present work extends the study of the Gaillardia inflorescence by examining the roles of plant hormones in the growth of the corolla of the ray flower.

The role of plant hormones in corolla ex-

\footnotetext{
1 Received for publication 10 September 1982; revision accepted 27 June 1983.

${ }^{2}$ Present address: Department of Biological SciencesBotany, Rutgers University, P.O. Box 1059, Piscataway, NJ 08854.

This work is part of a doctoral thesis submitted to the Rackham School of Graduate Studies, University of Michigan, Ann Arbor. The author is greatly indebted to Dr. Peter B. Kaufman (University of Michigan, Ann Arbor) for help with the manuscript and for equipment supplied through his NASA Grant NAGW-34. Dr. Jan Zeevaart, Dr. Robert Bandurski, and Dr. Jerry Cohen (Michigan State University, East Lansing) provided valuable advice for the endogenous hormone analyses.
}

pansion has been partially demonstrated for several genera. In the most complete studies of this involvement, gibberellins seem to be important (Blake, 1969; deJong and Bruinsma, 1974; Jeffcoat, Scott and Harris, 1969; Plack, 1958; Rao and Mohan Ram, 1979; Zieslin, Biran and Halevy, 1974), but the other hormones (auxins, cytokinins, ethylene, and abscisic acid) may also be implicated especially when hormone interactions are considered (deJong and Bruinśma, 1974). The effects of applied hormones, hormone synthesis, and hormone-action inhibitors have been used to help demonstrate regulatory roles for these hormones (deJong and Bruinsma, 1974; Rao and Mohan Ram, 1979). Studies showing parallel or inverse variation of endogenous hormone levels and corolla elongation add further support to the roles for the plant hormones in this growth process. Such correlations have been made for flower opening processes and auxin (Hatcher, 1945; Ilahi, 1979; Janardhan, Raju and Gopal, 1977), gibberellins (Alpi et al., 1976; Einert, Staby and DeHertogh, 1972; Leshem and Ophir, 1977; Murakami, 1973, 1975), cytokinins (Mayak and Halevy, 1970; Watanabe, Yokota and Takahashi, 1978), and ethylene (Beyer and Sundin, 1978; Blumenfeld, 1975) in various species. All of these studies have been done with plants having perfect flowers, where interactions between flower parts are important. In the present work, the roles of plant hormones have been elucidated by 
using of all of these approaches in the study of corolla growth in the sterile ray flower of Gaillardia which is relatively free of flower part interactions.

MATERIALS AND METHODS-Plant culturePlants of Gaillardia grandiflora Van Houtte cv. 'Goblin' were grown to flowering as described previously (Koning, 1983a). Each inflorescence produces 10 to 20 ray flowers that are genetically (derived from the same apical meristem) and developmentally (all flowers open simultaneously) similar. Ray flowers from the inflorescences of a single plant were used for each experiment.

Cell length and cell number determinations - Wet mounts of corollas were made, and the length of each epidermal cell in a medianlongitudinal row of adaxial cells was measured as described previously (Greyson and Tepfer, 1966; Koning, 1983a). Cell numbers in the row were also noted.

Fresh and dry weight determinationsGroups of 25 corollas at each developmental stage (Fig. 1) were weighed on a Sartorius Model 2603 analytical balance before and after overnight oven drying at $80 \mathrm{C}$.

In vitro corolla growth-Stage II corollas (10$11 \mathrm{~mm}$ ) were gently plucked from the inflorescences. The corollas from each inflorescence were divided equally among the several treatment dishes for a given experiment. Each 10$\mathrm{cm}$ petri (treatment) dish contained one microslide, a 9-cm-diam filter paper disc, and 6 $\mathrm{ml}$ of the test solution (all solutions contained $0.05 \mathrm{M}$ sucrose as a substrate for growth). Ten isolated corollas were placed horizontally on the moist paper over the microslide in each dish. The dishes were covered and incubated in the dark at $30 \mathrm{C}$ in a Thelco Model 2 incubator. The test solutions were replaced by moving the corollas to fresh treatment dishes after 48 and 96 hours, respectively. The corollas were measured at 24-hr intervals for 6 days. The corolla length was determined to within $0.5 \mathrm{~mm}$. The mean length was calculated for each treatment at every interval. Since corollas attained full size in 5 days in vivo, all dose responses reported represent means after 120 hours in vitro.

Test solutions ${ }^{3}-\mathrm{AbA}, \mathrm{BA}, \mathrm{CCC}, \mathrm{CoCl}_{2}$, IAA, IPA, PCIB, TIBA, and zeatin were obtained

\footnotetext{
${ }^{3}$ Abbreviations: AMO-1618: 4-hydroxy-5-isopropyl-2methyl-phenyl trimethyl ammonium chloride-1-piperi-
}

from Sigma Chemical Co., St. Louis, Missouri. AMO-1618 was obtained from Polysciences, Inc., Warrington, Pennsylvania; AVG was a gift from Maag Agrochemicals, Vero Beach, Florida; and FC was a gift from Montedison S.P.A., Milano, Italy. $\mathrm{GA}_{3}$ and $\mathrm{GA}_{4+7}$ were a gift from Imperial Chemical Industries Ltd., England, to P. B. Kaufman. Serial dilutions of 1-mM stock solutions of these compounds were used as test solutions. Ethylene $(1,000 \mathrm{nl} / 1)$ was obtained from Applied Sciences, State College, Pennsylvania, and the corollas were treated in rubber-scaled petri dishes by introducing the gas by syringe. The atmosphere was changed at 2-hr intervals in an exhaust hood.

Auxin analyses-The amount of endogenous auxin was determined for corollas at each stage of ray flower opening by using the double standard isotope dilution assay designed by Cohen and Schulze (1981) as described previously (Koning, 1983a). This method uses solvent partitioning, Sephadex A-25 column filtration, and high performance liquid chromatography (HPLC) for purification of auxin extracts. The analyses of purified auxins (with double internal standards) were made by gas chromatography with a nitrogen-phosphorus detector and scintillation counting.

Ethylene analyses-The amount of ethylene production was measured by gas chromatography for corollas at each stage of ray flower opening as described previously for disc flowers (Koning, 1983a).

Gibberellin analyses-The amount of endogenous gibberellin was estimated for corollas at each stage of opening as described previously (Koning, 1983b). This method uses the extraction and purification procedures of Jones, Metzger and Zeevaart (1980), which include charcoal-celite filtration, solvent partitioning, and preparative HPLC, and the 'Tan-ginbozu' dwarf rice bioassay developed by Murakami (1968). The dwarf rice seeds were a gift from Dr. R. P. Pharis, Calgary, Canada. Indicated values above $10^{-7} \mathrm{M} \mathrm{GA}_{3}$-equivalent were summed for the fractions of each extract of corollas at, the five stages of ray flower opening.

RESULTS AND DISCUSSION-Ray flower development-Five easily recognized stages were

dine carboxylate; AVG: aminoethoxyvinylglycine; CCC: 2-chloroethyltrimethyl ammonium chloride; FC: fusicoccin; $\mathrm{GA}_{4+7}$ : gibberellin $\mathrm{A}_{4}$ and $\mathrm{A}_{7}$ mixture; IPA: isopentenyladenine; PCIB: 4-chlorophenoxyisobutyric acid; TIBA: 2,3,5-triiodobenzoic acid. 


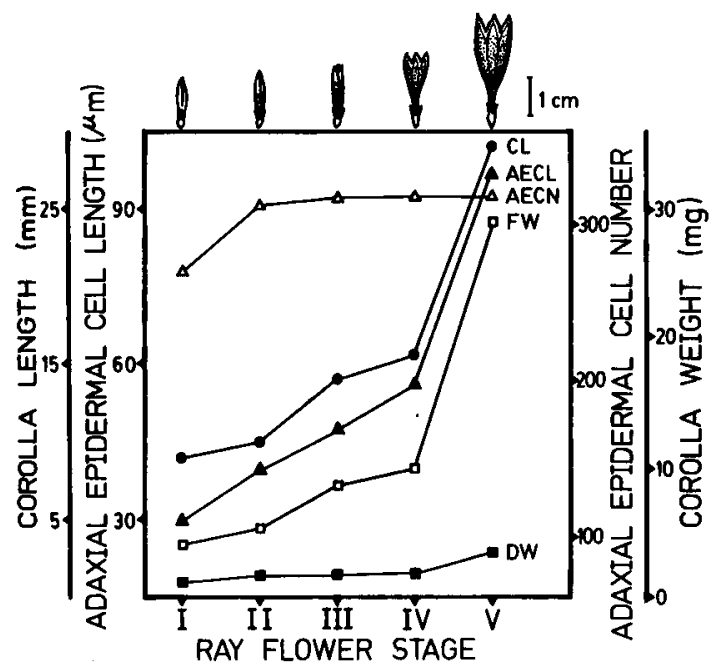

Fig. 1. Parameters of corolla growth. The mean corolla length (CLO) during the five stages of ray flower opening in Gaillardia is compared with changes in adaxial epidermal cell length (AECLA), adaxial epidermal cell numbers (AECN $\triangle$ ), fresh wt (FW $\square$ ), and dry wt (DWD) of the corollas.

established for opening ray flower buds (Fig. 1). In Stage I, the flower is relatively unpigmented and tightly closed. By Stage II, pigmentation has developed; the lobe tips are yellow, and the rest of the corolla is deep red. In Stage III, the flower tip opens and the corolla begins to unroll. By Stage IV, the corolla has unrolled completely, but it remains relatively unexpanded. The corolla has completely expanded by Stage $V$ and functions as an attraction device and landing platform for insect pollinators.

The elongation of the corolla is also shown in Fig. 1. The calyx and empty ovary do not elongate significantly during these stages (Koning, 1981). Ray flower opening is complete in 5 days, so the corolla makes the bulk of its expansion in the last 2 days. The corolla remains extended for 10 days during the subsequent development of all of the disc flowers in the inflorescence.

Parameters of corolla elongation-Investigators almost unanimously agree that corolla elongation is accompanied by cell elongation, cell expansion, and increases in both fresh and dry weight (Alpi et al., 1976; Berghoef and Bruinsma, 1979b; Camprubi and Nichols, 1978, 1979; Gopal, Venkataramanan and Raju, 1975; Greyson and Sawhney, 1972; Hanks and Rees, 1979; Janardhan et al., 1977; Moe and Kristoffersen, 1969; Murakami, 1975; Stark,

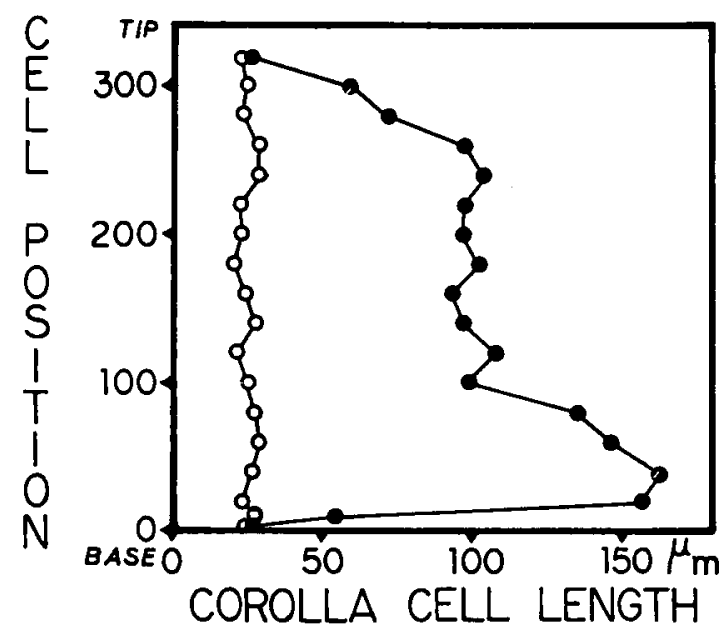

Fig. 2. Corolla adaxial epidermal cell length as a function of position in a median column of cells extending from the base of the corolla to the tip of the median lobe, both before $(0)$ and after $(0)$ elongation in Gaillardia ray flowers.

1982; Stead and Moore, 1977; Zieslin et al., 1974). The corollas of Gaillardia disc flowers do not expand during opening (Koning, 1981), but corollas of ray flowers do (Fig. 1). Corolla expansion was accompanied by rapid water uptake, a small increase in dry matter, and cell elongation in the adaxial epidermis, but not by cell division (Fig. 1). Cell division had stopped by Stage II and therefore did not contribute to the rapid elongation that occurred between Stages III and V. Cell elongation was not uniform along the length of the corolla (Fig. 2). Like Dianthus (Camprubi and Nichols, 1979), but unlike Crocus flowers (Stark, 1982), cell elongation was greatest in the cells near the base of the corolla, in the region where it becomes tubular. A few cells at the very base did not elongate; these may be part of the abscission zone for the corolla when it senesces. The mesophyll cells of the corolla were not examined because of heavy epidermal pigmentation, and the abaxial epidermis was not measured because of its many heavily-pigmented trichomes. However, free-hand sections revealed that the mesophyll is usually two cells thick.

The roles of plant hormones-Of the growth processes associated with flower opening (corolla, filament, style, and stigma elongation, and stigma unfolding), corolla elongation has been studied most extensively. The roles of the plant hormones are well-established, but vary from species to species. 


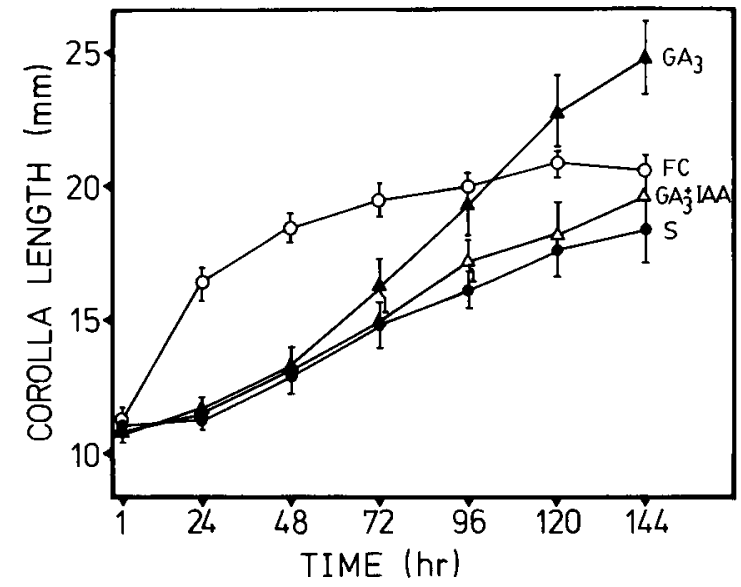

Fig. 3. The effects of growth regulators on the time course of growth in vitro of corollas excised from Stage II Gaillardia ray flower buds. The regulators: $10^{-4} \mathrm{M} F C(O)$, $10^{-6} \mathrm{M} \mathrm{GA}_{3}(\Delta)$, and $10^{-6} \mathrm{M} \mathrm{GA}_{3}$ with $10^{-6} \mathrm{M} \operatorname{IAA}(\Delta)$, were applied as test solutions containing $0.05 \mathrm{M}$ sucrose as a substrate for growth and are compared with $0.05 \mathrm{M}$ sucrose alone (๑). Vertical lines indicate $\pm \mathrm{SE}$.

Gibberellins-Hormone application studies have almost unanimously implicated the gibberellins as important regulators of corolla growth (Alpi et al., 1976; Berghoef and Bruinsma, 1979a, b; Blake, 1979; deJong and Bruinsma, 1974; Harris et al., 1969; Plack, 1958; Rao and Mohan Ram, 1979; Zieslin et al., 1974). The exceptions to this are the corollas of female Begonia flowers (Berghoef and Bruinsma, 1979a), which are inhibited by gibberellins, and Momordica flowers (Prakash, 1977), which do not respond to gibberellins. The promotion of ray flower growth in Gaillardia by applied gibberellins was dramatic and noticeable after $48 \mathrm{hr}$ in vitro (Fig. 3). The rate of growth and final size of corollas treated with gibberellins in vitro were comparable to those of corollas in vivo (Fig. 1). Both the more-polar $\mathrm{GA}_{3}$ and the less-polar $\mathrm{GA}_{4+7}$ promoted corolla elongation maximally at $10^{-6} \mathrm{M}$ and greater concentrations (Fig. 4).

The gibberellin synthesis inhibitors, CCC and AMO-1618, have little effect upon corolla elongation in Rosa (Zieslin et al., 1974) even though applied gibberellins promote the expansion of the petals. Similar results were obtained for Gaillardia (Table 1), which indicates that the compounds were not taken up or that gibberellin synthesis is less important than transport of gibberellins into the flower or conversion of bound or less active isomers to more active isomers within the flower. The latter processes are presumably insensitive to AMO-

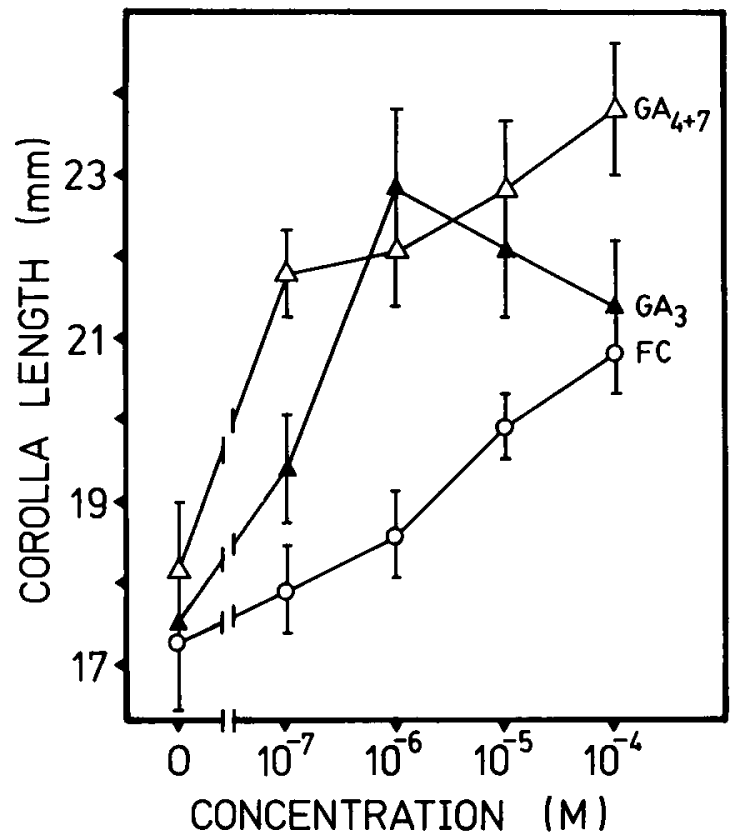

Fig. 4. Dose effects of $\mathrm{FC}(\mathrm{O}), \mathrm{GA}_{3}(\Delta)$, and $\mathrm{GA}_{4+7}(\triangle)$ on corolla length after $120 \mathrm{hr}$ in vitro. The corollas were excised from Stage II Gaillardia ray flower buds. Vertical lines indicate $\pm \mathrm{SE}$.

1618 and $\mathrm{CCC}$, but the modes of action of these compounds in Gaillardia have not been established.

The levels of native gibberellins show parallel variation with flower opening processes in several species (Alpi et al., 1976; Einert et al., 1972; Ilahi, 1979; Jeffcoat and Cockshull, 1972; Kaufman et al., 1976; Murakami, 1973, 1975; Sladký, 1972; Zieslin, Madori and Halevy, 1979). This variation usually includes an increase of native gibberellins just prior to rapid growth of the corolla. In contrast, native gibberellin content varies inversely with flower development in other species (Dathe and Sembdner, 1980; Leshem and Ophir, 1977; Wheeler, 1972). This form of variation may be equally causative; inhibiting levels of gibberellins may be reduced, allowing the flowers to open (Koning, 1981, 1983b). The bioassay results for extracts of Gaillardia ray flower corollas provide an interesting analysis of the gibberellins during development (Fig. 5). In Stage I, less-polar gibberellins predominated (fractions 17-22). By Stage III, more gibberellin activity was present, and more-polar gibberellins appeared (fractions 9-10). By Stage IV, the more-polar gibberellins predominated as the less-polar gibberellins had declined. The presence of inhibitors of the bioassay also con- 
TABLE 1. Treatments having no significant dose effect after $120 \mathrm{hr}$ in vitro on length of corollas excised from Stage II Gaillardia ray flower buds

\begin{tabular}{lccccc}
\hline \hline & \multicolumn{5}{c}{ Concentration $\mathrm{M}$} \\
\cline { 2 - 6 } Regulator & 0 & \multicolumn{5}{c}{$10^{-7}$} & $10^{-6}$ & $10^{-5}$ & $10^{-4}$ \\
\hline & & \multicolumn{4}{c}{ Mean corolla length \pm SE after $120 \mathrm{hr}$} \\
AMO 1618 & $18.2 \pm 1.1$ & $18.2 \pm 1.1$ & $17.8 \pm 0.8$ & $17.2 \pm 0.9$ & $18.0 \pm 1.5$ \\
CCC & $17.0 \pm 0.9$ & $16.8 \pm 1.0$ & $16.5 \pm 0.8$ & $16.4 \pm 0.8$ & $15.9 \pm 0.9$ \\
IAA & $17.6 \pm 1.1$ & $18.0 \pm 0.6$ & $18.4 \pm 1.2$ & $16.7 \pm 0.9$ & $17.7 \pm 0.7$ \\
TIBA & $18.4 \pm 1.1$ & $17.3 \pm 0.9$ & $17.2 \pm 0.6$ & $18.6 \pm 0.8$ & $11.2 \pm 0.3$ \\
PCIB & $17.8 \pm 1.3$ & $18.4 \pm 0.9$ & $19.7 \pm 0.9$ & $18.9 \pm 0.9$ & $18.7 \pm 1.1$ \\
AVG & $16.2 \pm 1.0$ & $15.8 \pm 0.6$ & $16.9 \pm 0.6$ & $16.9 \pm 1.0$ & $15.0 \pm 0.9$ \\
Co ${ }^{2+}$ & $15.7 \pm 0.7$ & $17.0 \pm 1.0$ & $15.7 \pm 0.7$ & $16.6 \pm 0.8$ & $17.9 \pm 1.0$ \\
Zeatin & $16.0 \pm 1.0$ & $16.9 \pm 0.9$ & $16.5 \pm 0.7$ & $16.8 \pm 1.2$ & $16.8 \pm 0.7$ \\
IPA & $16.2 \pm 1.1$ & $16.0 \pm 1.0$ & $15.2 \pm 0.8$ & $16.0 \pm 0.9$ & $16.8 \pm 0.7$ \\
BA & $16.2 \pm 1.0$ & $16.3 \pm 0.8$ & $16.7 \pm 0.8$ & $16.8 \pm 1.0$ & $17.9 \pm 1.1$ \\
AbA & $16.2 \pm 0.5$ & $15.4 \pm 0.7$ & $16.5 \pm 0.5$ & $15.8 \pm 0.5$ & $16.3 \pm 0.6$ \\
Ethylene @ $10 \mathrm{nl} / \mathrm{l}:$ & $16.0 \pm 0.5$ & & & &
\end{tabular}

tinued to decline throughout development, but these may represent artifacts due to disruption of cell and tissue compartmentation. When the total gibberellin activity was summed and appropriate calculations were made, the gibberellin activity showed a 20 -fold increase between Stages II and III, and the high level was maintained in the corollas during Stage IV when corolla elongation began (Fig. 6). The peak level of gibberellin activity occurred at the appropriate stage of development (IV) and translated to a dissolved gibberellin concentration of $10^{-6}$ $\mathrm{M} \mathrm{GA}_{3}$-equivalent, an amount capable of inducing maximal growth and normal growth kinetics in vitro (Fig. 3, 1). Thus it appears that gibberellin is a limiting factor in growth of the Gaillardia ray flower corolla.

Auxin-Auxin has been reported to stimulate (Goldschmidt and Huberman, 1974; Jeffcoat, 1977: Prakash, 1977; Stark, 1982), to have no effect on (Berghoef and Bruinsma, 1.979b; Blake, 1969; deJong and Bruinsma, 1974; Zieslin et al., 1974), and to inhibit (lizuka and Hashizume, 1968; Murakami, 1975) corolla elongation in various species. Gaillardia ray flower corollas did not respond significantly to applied auxin (Table 1), but when auxin was applied simultaneously with gibberellin, it prevented the promoting effect of the gibberellin (Fig. 3). Thus, auxin could act as a negative modulator of gibberellin activity in developing ray flowers.

The auxin transport inhibitor, TIBA, had no effect upon corolla elongation in Cleome (deJong and Bruinsma, 1974), and neither TIBA nor PCIB, an auxin action inhibitor, had any effect upon corolla elongation in Gaillardia (Table 1) except at a toxic concentration $\left(10^{-4}\right.$ M; TIBA is obviously taken up by the tissues).

Parallel variation of IAA levels and corolla growth has been demonstrated in several species (Gopal and Venkataramanan, 1976; Hänischtencate et al., 1975; Hatcher, 1945; Ilahi, 1979; Janardhan et al., 1977; Jeffcoat and Cockshull, 1972; Sladký, 1972; Zieslin et al., 1979). In Gaillardia, the IAA level in ray flower corollas remained constant throughout development (Fig. 6), which is consistent with its ineffectiveness in vitro (Table 1) and rules out any role as a negative modulator of gibberellin activity in vivo.

Ethylene-Ethylene has been reported to stimulate (Camprubi and Nichols, 1979; Prakash, 1977), to have no effect on (Berghoef and Bruinsma, 1979a, b; Beyer, 1977; Beyer and Sundin, 1978), and to inhibit (deJong and Bruinsma, 1974) corolla elongation in various species. Applied ethylene had no effect on elongation of the corolla of Gaillardia ray flowers (Table 1) but completely prevented corolla unrolling (data not shown).

The effects of ethylene biosynthesis inhibitors have not been reported in other species, but $A V G$ and $\mathrm{CO}^{2+}$ had no effect on corolla elongation or unrolling in Gaillardia (Table 1).

Ethylene production seems to be correlated most commonly with petal senescence (Eisinger, 1977; Mayak and Dilley, 1976; Mayak and Halevy, 1972; Mayak, Halevy and Katz, 1972; Nichols, 1977; Wheeler, 1972). In Gaillardia ray flower corollas, a burst of ethylene synthesis occurred well before corolla growth, and production was somewhat reduced at the time of 

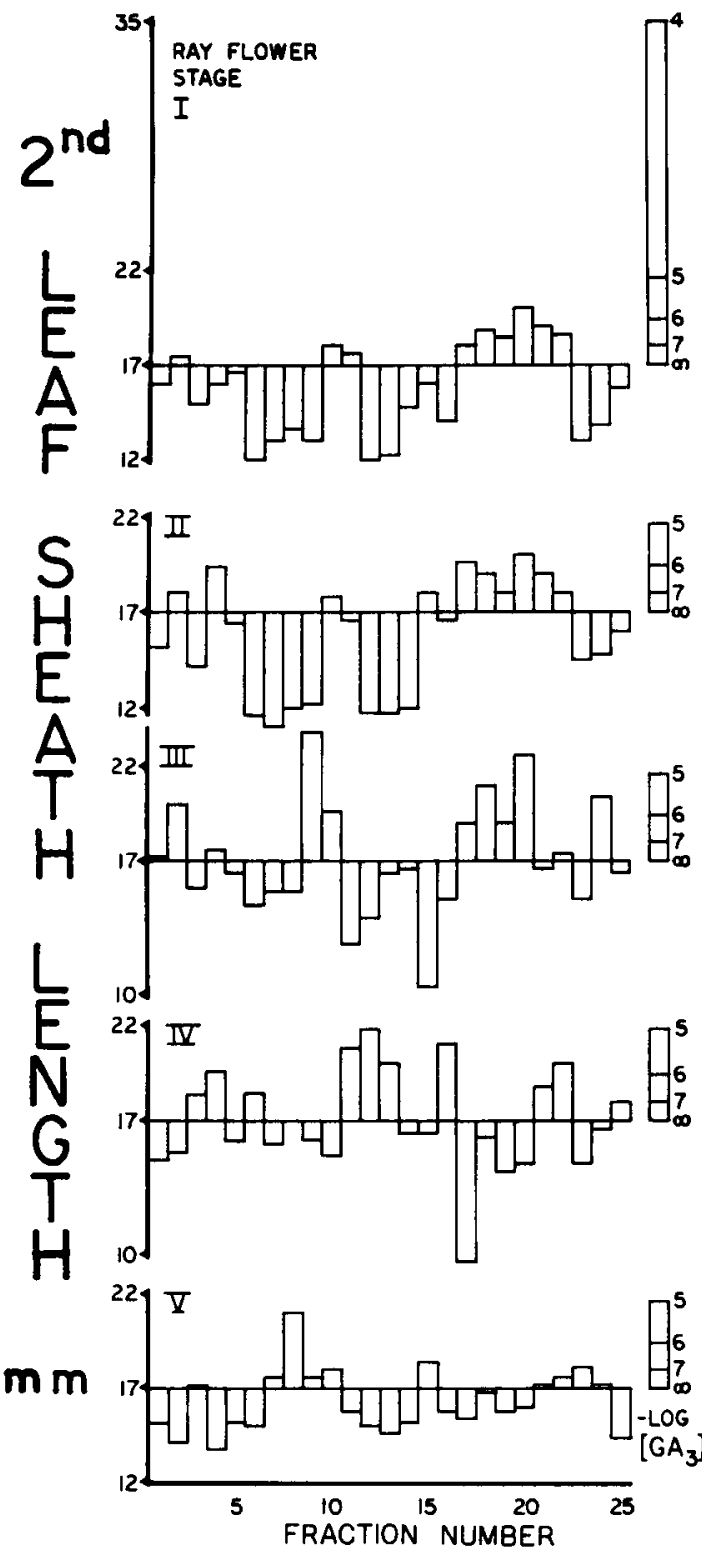

Fig. 5. The gibberellin content of HPLC-separated fractions of extracts of Gaillardia ray flower corollas at the five stages of flower opening, as determined by the 'Tanginbozu' dwarf rice bioassay.

corolla unrolling (Fig. 6). Perhaps the ethylene prevents unrolling until the appropriate time in development.

Cytokinins-Cytokinins have been reported to stimulate (Berghoef and Bruinsma, 1979a; Jeffcoat, 1977), to have no effect on (deJong and Bruinsma, 1974; Jeffcoat, 1977; Prakash, 1977; Stark, 1982; Zieslin et al., 1974), and to

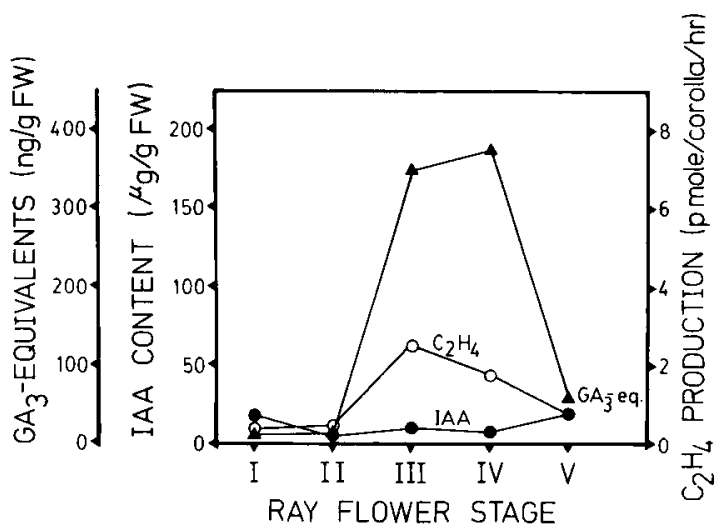

Fig. 6. Levels of $\mathrm{GA}_{3}$-equivalents (4), IAA (๑), and ethylene production $(O)$ in ray flower corollas during the five stages of flower opening in Gaillardia.

inhibit (Blake, 1969) corolla elongation in various species. Furthermore, parallel variation of native cytokinin levels and flower opening has been demonstrated in a few species (Mayak et al., 1972; Watanabe et al., 1978; Wheeler, 1972). In Gaillardia, the ray flower corollas did not respond to natural (zeatin, IPA) or synthetic (BA) cytokinins (Table 1). Since only cell elongation is involved in Gaillardia corolla growth, cytokinins are probably more important during flower primordia differentiation (Hicks and Sussex, 1970), when cell division is predominant, and in delaying flower senescence (Mayak and Halevy, 1974).

Abscisic acid-Abscisic acid has been shown to stimulate (Borochov, Mayak and Halevy, 1976; Prakash, 1977), to have no effect on (Berghoef and Bruinsma, 1979a, b; Zieslin et al., 1974), and to inhibit (deJong and Bruinsma, 1974; Prakash, 1977) corolla elongation in various species. The corollas of Gaillardia did not respond to abscisic acid applications (Table 1).

Hormone interactions-In Cleome, growth promotion by gibberellins can overcome growth inhibition by $\mathrm{AbA}$ (deJong and Bruinsma, 1974); cytokinins have no effect upon elongation alone but can enhance gibberellin-promoted growth and can overcome inhibition by ethylene and AbA. In Gaillardia, simultaneous and sequential applications of maximum-response concentrations of hormones showed no significant synergistic, additive, or antagonistic relationships (Koning, 1981) other than the gibberellin-auxin interaction discussed and refuted previously. 
Gibberellin mode of action-Gibberellins are known to induce proton pumping in stem elongation (Hebard et al., 1976). The reduction of pH may activate cell-wall-loosening enzymes and thereby increase the plasticity of the cell walls (Adams et al., 1975). Turgor pressure may then cause elongation of the cells.

Fusicoccin is a potent stimulator of proton efflux and promotes most acid-responsive systems (Marré, 1979; Koning, 1981, 1983a,b). Corolla growth has been shown to be an acidresponsive system (Berghoèf and Bruinsma, $1979 \mathrm{~b}$ ), and fusicoccin stimulated the elongation of Gaillardia ray flower corollas significantly after one day (Fig. 3). In fact, the dose response after two days (Koning, 1981) was steeper than after 5 days (Fig. 4) in vitro. The growth kinetics for $10^{-7} \mathrm{M}$ fusicoccin were the same as those for $10^{-7} \mathrm{M} \mathrm{GA}_{3}$ (Koning, 1981). These results support the hypothesis that gibberellin action may be partially an acid-induced growth mechanism. The failure of fusicoccin to increase the final size of the corollas, unlike $\mathrm{GA}_{3}$ (Fig. 3), indicates that gibberellin action is more than just acid-induced growth.

In conclusion, it appears that the elongation of the corolla in the Gaillardia ray flower is controlled simply by the level of endogenous gibberellin activity and is not controlled by other plant hormones or their interactions with gibberellins. These gibberellins may serve only partially to induce acid growth in the corolla and apparently have additional functions. The gibberellins are converted from less-polar isomers during development, and this may be responsible for most of the increase in gibberellin activity that induces corolla growth; gibberellin synthesis inhibitors did not reduce corolla growth in vitro.

\section{LITERATURE CITED}

Adams, P. A., M. J. Montague, M. Tepfer, D. L. Rayle, H. IKuma, AND P. B. Kaufman. 1975. Effect of gibberellic acid on the plasticity and elasticity of $A$ vena stem segments. Plant Physiol. 56: 757-760.

Alpi, A., N. Ceccarelli, F. Tognoni, and G. Gregorini. 1976. Gibberellin and inhibitor content during Iris bulb development. Physiol. Plant. 36: 362-367.

Berghoef, J., AND J. BRUINSMA. 1979a. Flower development of Begonia franconis Liebm. I. Effects of growth-regulating substances and environmental conditions on the composition of the inflorescence. $Z$. Pflanzenphysiol. 93: 303-315.

$\longrightarrow$, AND 1 1979b. Flower development of $B e-$ gonia franconis Liebm. II. Effects of nutrition and growth-regulating substances on the growth of flower buds in vitro. Z. Pflanzenphysiol. 93: 345-357.

BEYER, E. M., JR. $1977 .{ }^{14} \mathrm{C}_{2} \mathrm{H}_{4}$ : its incorporation and oxidation to ${ }^{14} \mathrm{CO}_{2}$ by cut carnations. Plant Physiol. 60: 203-206.

—, AND O. SUNDIN. 1978. ${ }^{14} \mathrm{C}_{2} \mathrm{H}_{4}$ metabolism in morning glory flowers. Plant Physiol. 61: 896-899.
BLAKE, J. 1969. The effect of environmental and nutritional factors on the development of flower apices cultured in vitro. J. Exp. Bot. 20: 113-123.

Blumenfeld, A. 1975. Ethylene and the Annona flower. Plant Physiol. 55: 265-269.

Borochov, A., S. Mayak, and A. H. Halevy, 1976. Combined effects of abscisic acid and sucrose on growth and senescence of rose flowers. Physiol. Plant. 36: 221-224.

Camprubi, P., and R. Nichols. 1978. Effects of ethylene on carnation flowers (Dianthus caryophyllus) cut at different stages of development. J. Hort. Sci. 53: 1722.

, AND —. 1979. Ethylene-induced growth of petals and styles in the immature carnation inflorescence. J. Hort. Sci. 54: 225-228.

Cohen, J. D., AND A. Schulze. 1981. Double standard isotope dilution assay. I. Quantitative assay of indole3-acetic acid. Anal. Biochem. 112: 249-257.

Dathe, W., AND G. Sembdner. 1980. Endogenous plant hormones of the broad bean, Vicia faba L. II. Gibberellins and plant growth inhibitors in floral organs during their development. Biochem. Physiol. Pflanzen 175: 599-610.

DeJong, A. W., And J. Bruinsma. 1974. Pistil development in Cleome flowers. III. Effects of growth-regulating substances on flower buds of Cleome iberidella Welw. ex Oliv. grown in vitro. Z. Pflanzenphysiol. 73: 142-151.

Einert, A. E., G. L. Staby, and A. A. DeHertogh. 1972 Gibberellin-like activity from organs of Tulipa ges neriana. Can. J. Bot. 50: 909-914.

EISINGER, W. 1977. Role of cytokinins in carnation flower senescence. Plant Physiol. 59: 707-709.

GoldschmidT, E. E., AND M. Huberman. 1974. The coordination of organ growth in developing citrus flowers: a possibility for sink type regulation. J. Exp. Bot. 25: 534-541.

Gopal, N. H., And N. Vasudeva. 1973. Physiological studies on flowering in arabica coffee under South Indian conditions. I. Growth of flower buds and flowering. Turrialba 23: 146-153.

, and D. Venkataramanan. 1976. Physiological studies on flowering in coffee under South Indian conditions. V. Growth-substance content during flower bud enlargement and anthesis. Turrialba 26: 74-79.

,-- , ANDK. I. RAJU. 1975. Physiological studies on flowering in coffee under South Indian conditions. II. Changes in water content, growth rate, respiration and carbohydrate metabolism of flower buds during bud enlargement and anthesis. Turrialba 25 $29-36$.

Greyson, R. I., ANd V. K. SAwhney, 1972. Initiation and early growth of flower organs of Nigella and $L y$ copersicon: insights from allometry. Bot. Gaz. 133: 184-190.

- _ AND S. S. TEPFER. 1966. An analysis of stamen filament growth of Nigella hispanica. Amer. J. Bot. 53: 485-490.

Hänischtencate, C. H., J. Berghoef, A. M. H. VanDerHoorn, AND J. Bruinsma. 1975. Hormonal regulation of pedicel abscission in Begonia flower buds. Physiol. Plant. 33: 280-284.

Hanks, G. R., And A. R. Rees. 1979. Photoperiod and tulip growth. J. Hort. Sci. 54: 39-46.

Harris, G. P., B. JefFcoat, and J. F. Garrod. 1969. Control of flower growth and development by gibberellic acid. Nature 223: 1071.

HatCher, E. S. J. 1945. Studies on the vernalisation of 
cereals. IX. Auxin production during development and ripening of the anther and carpel of spring and winter rye. Ann. Bot. 9: 235-266.

Hebard, F. V., S. J. Amatangelo, P. Dayanandan, and P. B. Kaufman. 1976. Studies on acidification of media by Avena stem segments in the presence and absence of gibberellic acid. Plant Physiol. 58: 670674.

Hicks, G. S., AND I. M. Sussex. 1970. Development in vitro of excised flower primordia of Nicotiana tabacum. Can. J. Bot. 48: 133-139.

IizuKA, M., AND T. Hashizume. 1968. Induction of female organs in staminate grape by 6 -substituted adenine derivatives. Jpn. J. Genet. 43: 393-394.

ILAHI, I. 1979. Nature and balance of growth regulators in the reproductive organs of Ceratonia siliqua $\mathrm{L}$. Phyton 37: 29-34.

Janardhan, K. V., K. I. Raju, and N. H. Gopal. 1977. Physiological studies on flowering in coffee under South Indian conditions. VI. Changes in growth rate, indoleacetic acid and carbohydrate metabolism during flower bud development and anthesis. Turrialba 27: 29-36.

JEFFCOAT, B. 1977. Influence of the cytokinin, 6-benzylamino-9-(tetrahydropyran-2-yl)-9H-purine, on the growth and development of some ornamental crops. J. Hort. Sci. 52: 143-153.

$\longrightarrow$, AND K. E. CoCKshull. 1972. Changes in the levels of endogenous growth regulators during development of the flowers of Chrysanthemum morifolium. J. Exp. Bot. 23: 722-732.

- M. A. Scott, ANd G. P. Harris. 1969. Studies on the glasshouse carnation: the detection of gibberellin-like substances in the flower and an effect of gibberellic acid on petal growth. Ann. Bot. 33: 515521 .

Jones, M. G., J. D. Metzger, And J. A. D. ZeevaArt. 1980. Fractionation of gibberellins in plant extracts by reverse-phase high performance liquid chromatography. Plant Physiol. 65: 218-221.

Kaufman, P. B., N. S. Ghosheh, L. Nakosteen, R. P. Pharis, R. C. Durley, and W. Morf. 1976. Analysis of native gibberellins in the internode, nodes, leaves, and inflorescence of developing Avena plants. Plant Physiol. 58: 131-134.

Koning, R. E. 1981. Control of flower opening by plant hormones in Gaillardia grandiflora. Ph.D. thesis, University of Michigan, Ann Arbor.

- 1983a. The roles of auxin, ethylene, and acid growth in filament elongation in Gaillardia grandiflora (Asteraceae). Amer. J. Bot. 70: 602-610.

- 1983b. The roles of plant hormones in style and stigma growth in Gaillardia grandiflora (Asteraceae). Amer. J. Bot. 70: 978-986.

Leshem, Y., AND D. OPHIR. 1977. Differences in endogenous levels of gibberellin activity in male and female partners of two dioecious tree species. Ann. Bot. 41: 375-379.

MARRÉ, E. 1979. Fusicoccin: a tool in plant physiology. Annu. Rev. Plant Physiol. 30: 273-312.

MAYAK, S., AND D. R. Dilley. 1976. Regulation of senescence in carnation (Dianthus caryophyllus). Effect of abscisic acid and carbon dioxide on ethylene production. Plant Physiol. 58: 663-665.
, AND A. H. Halevy. 1970. Cytokinin activity in rose petals and its relation to senescence. Plant Physiol. 46: 497-499.

— AND —. 1972. Interrelationships of ethylene and abscisic acid in the control of rose petal senescence. Plant Physiol. 50: 341-346.

$\longrightarrow$, AND - 1974. The action of kinetin in improving the water balance and delaying senescence processes of cut rose flowers. Physiol. Plant. 32: 330336.

, AND M. KATZ. 1972. Correlative changes in phytohormones in relation to senescence processes in rose petals. Physiol. Plant. 27: 1-4.

MOE, R., AND T. KRISTOFFERSEN. 1969. The effect of temperature and light on growth and flowering of Rosa 'Baccara' in greenhouses. Acta Hort. 14: 157-166.

Murakami, Y. 1968. A new rice seedling test for gibberellins, 'microdrop method,' and its use for testing extracts of rice and morning glory. Bot. Mag. 81: 3343.

- 1973. The role of gibberellins in the growth of floral organs of Pharbitis nil. Plant Cell Physiol. 14: 91-102.

. 1975. The role of gibberellins in the growth of floral organs of Mirabilis jalapa. Plant Cell Physiol. 16: 337-345.

Nichols, R. 1977. Sites of ethylene production in the pollinated and unpollinated senescing carnation (Dianthus caryophyllus) inflorescence. Planta 135: 155159.

Plack, A. 1958. Effect of gibberellic acid on corolla size. Nature 182: 610.

PrakAsh, G. 1977. Plant growth regulators and sex expression in flower buds of Momordica charantia in vitro. Curr. Sci. 46: 328-330.

RAO, I. V. R., AND H. Y. MOHAN RAM. 1979. Interaction of gibberellin and sucrose in flower bud opening in gladiolus. Ind. J. Exp. Biol. 17: 447-448.

SLADKÝ, Z. 1972. The role of endogenous growth regulators in the differentiation processes of walnut $(J u$ glans regia L.). Biol. Plant. 14: 273-278.

STARK, D.S. P. 1982. Anatomical and physiological studies of floral tube elongation of Crocus vernus (Iridaceae). Amer. J. Bot. 69: 1476-1482.

Stead, A. D., AND K. G. Moore. 1977. Flower development and senescence in Digitalis purpurea L., cv. Foxy. Ann. Bot. 41: 283-292.

Watanabe, N., T. Yokota, AND N. Takahashi. 1978. Identification of zeatin and zeatin riboside in cones of the hop plant and their possible role in cone growth. Plant Cell Physiol. 19: 617-625.

WheELER, A. W. 1972. Changes in growth-substance contents during growth of wheat grains. Ann. Appl. Biol. 72: 327-334.

Zieslin, N., I. Biran, and A. H. Halevy. 1974. The effect of growth regulators on the growth and pigmentation of 'Baccara' rose flowers. Plant Cell Physiol. 15: 341-349.

, G. MADORI, AND A. H. Halevy. 1979. Involvement of hormonal balance in the control of the "bullhead' malformation in Baccara rose flowers. J. Exp. Bot. 30: 15-25. 